\section{Frequência de Escherichia coli e sua sensibilidade aos antimicrobianos em menores de cinco anos hospitalizados por diarreia aguda}

\section{The frequency of Escherichia coli and its sensitivity to antimicrobials in children aged under five years admitted to hospital for treatment of acute diarrhea}

\begin{abstract}
Objectives: to determine the frequency of diarrheic Escherichia coli and its sensitivity to antimicrobials in children aged under five years admitted to hospital for treatment of acute diarrhea.

Methods: a prospective cross-sectional study was carried out at the Instituto de Medicina Integral Prof. Fernando Figueira, between January 2010 and February 2011. Children were excluded if they had been diagnosed as immunodeficient or were using antimicrobials. A single rectal swab was taken from each patient during the first 24 hours of hospitalization. The pathogens were identified in the coproculture and serotyping. Antibiograms were obtained using disc-diffusion.

Results: 140 children were recruited. Most were from low-income families in the Metropolitan Region of Recife. Ninety-nine micro-organisms were isolated: 9 (6.4\%) enteropathogenic E. coli (EPEC) and 4 (2.9\%) enteroinvasive E. coli (EIEC) and $80(57.1 \%)$ other E.coli that are neither EPEC nor EIEC, 3 (2.1\%) Shigella spp and 3 (2.1\%) Salmonella spp. The profile of sensitivity to antimicrobials showed high levels to resistance to ampicillin and sulfamethoxazol-trimetropime.

Conclusions: the low frequency of EPEC found may be associated with basic sanitary conditions among the patients in the study. The local analysis of the profile of sensitivity of E. coli to antimicrobials corroborates the World Health Organization recommendation that these drugs be used prudently to ensure prevention of resistance in bacteria.
\end{abstract}

Key words Diarrhea, infantile, Child, Escherichia coli, Drug resistance, bacterial
Maria do Rosário S. de Almeida Lélis de Moura 1 Maria Júlia Gonçalves de Mello 2 Waldylene Barbosa Calábria 3 Eliane Mendes Germano 4 Ruben Rolando Schindler Maggi 5 Jailson de Barros Correia 6

1,3 Laboratório de Análises Clínicas. Instituto de Medicina Integral Prof. Fernando Figueira. Recife, PE, Brasil.

2,4,5,6 Programa de Pós-Graduação em Saúde Materno Infantil. Instituto de Medicina Integral Prof. Fernando Figueira. Rua dos Coelhos, 300. Boa Vista. Recife, PE, Brasil. CEP: 50.070-550. E-mail: mjuliagmello@gmail.com

\section{Resumo}

Objetivos: determinar a frequência de Escherichia coli diarreiogênica e sua sensibilidade aos antimicrobianos em menores de cinco anos hospitalizados por diarreia aguda.

Métodos: estudo prospectivo tipo corte transversal realizado no Instituto de Medicina Integral Prof. Fernando Figueira, entre janeiro de 2010 e fevereiro de 2011. Foram excluidas as crianças com diagnóstico de imunodeficiência ou usando antimicrobianos. Para cada paciente foi feito uma única coleta de swab retal nas primeiras 24 horas de internação. Os patógenos foram identificados na coprocultura e sorotipagem. Os antibiogramas foram obtidos por disco-difusão.

Resultados: 140 crianças foram arroladas, em sua maioria provinham de famílias de baixa renda da Região Metropolitana do Recife. Foram isolados 99 microorganismos: $9(6,4 \%)$ E. coli enteropatogênica (EPEC) e 4 (2,9\%) E. coli enteroinvasora (EIEC) e $80(57,1 \%)$ outras E.coli não EPEC, não EIEC, 3 $(2,1 \%)$ Shigella spp e $3(2,1 \%)$ Salmonella spp. $O$ perfil de sensibilidade aos antimicrobianos demonstrou niveis elevados de resistência à ampicilina e sulfametoxazol-trimetoprima.

Conclusões: a baixa frequência de EPEC observada pode estar associada às condições de saneamento básico favoráveis apresentadas pelos pacientes do estudo. A análise local do perfil da sensibilidade da E. coli aos antimicrobianos reforça a recomendação da Organização Mundial de Saúde para o uso racional dessas drogas visando prevenção da resistência bacteriana.

Palavras-chave Diarreia infantil, Criança, Escherichia coli, Resistência bacteriana a antibióticos 


\section{Introdução}

As doenças diarreicas são causas importantes de morbimortalidade em crianças menores de cinco anos em todo o mundo, estando associadas a diversos fatores socioeconômicos, demográficos e culturais, mas, sobretudo à pobreza, desmame precoce, deficiências nutricionais e menor nível de escolaridade materna. ${ }^{1-3}$ Entretanto, as mortes por diarreia diminuíram substancialmente nas últimas décadas, principalmente devido ao advento da terapia de reidratação oral (TRO) ${ }^{1}$ e à introdução de vacinas para rotavírus.4-6 Considerando que o rotavírus é o agente etiológico mais frequente de diarreia grave em menores de cinco anos, a redução do número de casos de diarreia grave por este agente implica em uma necessária revisão dos aspectos epidemiológicos que norteiam o planejamento das intervenções em saúde. Outros agentes infecciosos bacterianos poderiam apresentar maior importância relativa na etiologia e, por conseguinte, no manejo da doença diarreica aguda.4-6

Os enteropatógenos bacterianos mais frequentemente associados à diarreia aguda na criança são a Escherichia coli, Shigella spp, Salmonella spp, Campylobacter spp e o Vibrio cholerae, este último, sobretudo em surtos epidêmicos. 1

A Escherichia coli é um bacilo gram-negativo, anaeróbio facultativo, predominante na microbiota normal do intestino humano e em outras espécies animais. As cepas de E. coli envolvidas com infecções intestinais foram denominadas $E$. coli diarreiogênicas (DEC) e sua classificação se dá por sorogrupos $\mathrm{O}$ e sorotipos $\mathrm{O}: \mathrm{H}$. Atualmente as DEC são classificadas em seis categorias ou patotipos de acordo com características clínicas, epidemiológicas e presença de fatores de virulência: E. coli enteropatogênica (EPEC), E. coli enterotoxigênica (ETEC), E. coli entero-hemorrágica (EHEC) ou produtora de toxina Shiga (STEC), E. coli enteroinvasora (EIEC), E. coli enteroagregativa (EAEC) e $E$. coli que adere difusamente (DAEC). ${ }^{7}$

A E. coli enteropatogênica é causa importante de diarreia infantil nos países em desenvolvimento. 7,8 No Brasil, estudos realizados no final dos anos 1990, demostraram que a EPEC era um dos mais importantes agentes etiológicos da diarreia aguda em crianças menores de dois anos pertencentes às classes socioeconômicas menos favorecidas. ${ }^{8,9} \mathrm{~A} E$. coli enteroinvasora apresenta características bioquímicas, genéticas e patogênicas semelhantes às da Shigella ${ }^{10}$ com quadro clínico de diarreia aquosa, seguida da evolução para disenteria na minoria dos casos. A maioria dos estudos epidemiológicos relata a presença de EIEC em surtos. ${ }^{7}$ No Brasil, estudo também realizado no final dos anos 1990, com crianças menores de cinco anos com diarreia aguda observou frequências para EIEC entre 0,5 e 1\%.11

A E. coli enterotoxigênica é considerada a principal causa de diarreia dos viajantes. ${ }^{7,12}$ A E. coli entero-hemorrágica está associada à síndrome hemolítica urêmica (SHU) ${ }^{10}$ e surtos, dentre eles, o mais recente, ocorrido no ano de 2011 na Alemanha. ${ }^{13} \mathrm{~A}$ E. coli enteroagregativa é considerada um enteropatógeno emergente e foi identificada inclusive em países industrializados. ${ }^{14} \mathrm{~A}$ E. coli que adere difusamente é causa de diarreia principalmente em crianças maiores de 12 meses de idade.7,10

Embora apresentem prevalências mais baixas que a $E$. coli em crianças menores de cinco anos, bactérias do gênero Shigella e Salmonella são importantes patógenos associados à diarreia, sobretudo quando as fezes são disentéricas. 8,9

Segundo dados do Ministério da Saúde do Brasil publicados em 2009, as mortes proporcionais por doença diarreica aguda corresponderam a $3,1 \%$ das mortes de crianças menores de cinco anos tendo Pernambuco apresentado o maior número de óbitos em relação a todos os Estados brasileiros (220 mortes). 15 No Instituto de Medicina Integral Prof. Fernando Figueira (IMIP), entidade filantrópica que atende exclusivamente pacientes do Sistema Único de Saúde, os atendimentos anuais e internamentos por diarreia vêm decrescendo. Em 2010 foram realizados 286 internamentos de crianças menores de cinco anos com diarreia correspondendo a 3,0\% dos 9658 internamentos clínicos.

Considerando a carência de estudos recentes em Pernambuco sobre a etiologia bacteriana da diarreia aguda na era pós-vacinal para rotavírus, este estudo tem como finalidade determinar a frequência e a sensibilidade da E.coli diarreiogênica incluindo EPEC e EIEC aos antimicrobianos nas diarreias agudas em crianças menores de cinco anos, hospitalizadas em serviço pediátrico de referência na região nordeste do Brasil.

\section{Métodos}

Foi realizado estudo descritivo, analítico e prospectivo, tipo corte transversal envolvendo crianças menores de cinco anos hospitalizadas com diarreia aguda no Instituto de Medicina Integral Prof. Fernando Figueira, Recife, Pernambuco, durante o período de janeiro de 2010 a fevereiro de 2011. As crianças admitidas por diarreia aguda foram recrutadas para o estudo nas primeiras 24 horas de internação. Considerou-se diarreia aguda quando o acom- 
panhante referia a presença nas 24 horas de pelo menos uma evacuação com sangue visível ou a presença de três ou mais evacuações de consistência diminuída tendo o episódio duração menor ou igual a 14 dias.1,2 Foram excluídas do estudo crianças em uso de antimicrobianos e aquelas com diagnóstico conhecido de imunodeficiência congênita ou adquirida.

Após consentimento dos responsáveis pela criança foi coletada uma única amostra de material fecal através de $s w a b$ retal que foi mantido em meio de transporte Cary Blair e encaminhado ao Laboratório de Análises Clínicas do IMIP. Foram obtidas por entrevista com os responsáveis do paciente e/ou secundariamente dos prontuários clínicos informações socioeconômicas-demográficas, antecedentes clínicos e caracterização/ evolução do episódio diarréico apresentado pela criança. $\mathrm{O}$ estado vacinal em relação ao rotavírus foi conferido pelo cartão de vacinas/caderneta de saúde da criança.

Cada amostra de material fecal foi semeada em placas de ágar MacConkey e ágar SS e incubadas durante 18 a 24 horas (estufa entre $35-37^{\circ} \mathrm{C}$ ). Colônias fermentadoras de lactose $(\mathrm{Lac}+)$ sugestivas de $E$. coli e as não fermentadoras (Lac -) sugestivas de EIEC, Shigella ou Salmonella, foram selecionadas para identificação bioquímica. Depois de caracterizadas bioquimicamente, as colônias sugestivas de E. coli, Shigella spp. e Salmonella spp. foram submetidas aos testes de aglutinação em lâmina com antissoros específicos polivalentes de acordo com as instruções do fabricante (PROBAC $\mathbb{R}$ do Brasil). Para detecção de E. coli enteropatogênica (EPEC) os antissoros usados foram polivalente A (O26, O55, O111 e O119), B (O114, O125, O142 e O158) e C (O86, O126, O127 e O128). Para a E. coli enteroinvasora (EIEC) foi usado o antissoro polivalente A (O28ac, O29, O136, O144, e O152) e B (O112ac, O124, O143, O164 e O167). O soro polivalente anti-Shigella foi utilizado para a identificação das espécies de Shigella e o soro polivalente anti-Salmonella para confirmação do gênero Salmonella. Foram consideradas positivas as reações de aglutinação completas que ocorreram dentro de dois minutos.

O antibiograma, método de disco-difusão em ágar Mueller Hinton (Kirby-Bauer), seguiu a padronização do Clinical and Laboratory Standards Institute (CLSI). 16 Foram testados os seguintes discos de antimicrobianos (CEFAR ${ }^{\circledR}$, S. Paulo, Brasil): ácido nalidíxico - 30 $\mu \mathrm{g}$; ampicilina - $10 \mu \mathrm{g}$; ceftazidima - $30 \mu \mathrm{g}$; ceftriaxona - $30 \mu \mathrm{g}$;

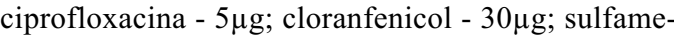

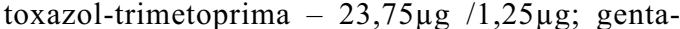
micina - $10 \mu \mathrm{g}$; amicacina - $30 \mu \mathrm{g}$. Para o controle de qualidade do meio de cultura e dos antimicrobianos empregados, foram utilizadas as cepas padrão determinadas pelo CLSI.

Os dados foram digitados em dupla entrada, analisados no programa EpiInfo versão 3.5.1. Para a análise de associação entre as variáveis foi utilizada a razão entre as prevalências, intervalo de confiança (IC95\%) e o teste de qui-quadrado de Pearson ou teste exato de Fisher.

O estudo foi aprovado pelo Comitê de Ética em Pesquisa (CEP) do IMIP sob o número 1626/2009.

\section{Resultados}

Foram incluídas no estudo 140 crianças e durante a hospitalização uma delas foi a óbito $(0,7 \%)$. As crianças eram provenientes predominantemente da Região Metropolitana do Recife $(69,3 \%)$ e as suas condições socioeconômicas e demográficas estão apresentadas na Tabela 1. A maioria possuía renda per capita mensal familiar inferior ou igual a meio salário mínimo regional (SMR 2010 foi $\mathrm{R} \$ 510,00 \mathrm{ou}$ U\$247,20), morava em habitação permanente com abastecimento de água através de canalização interna; as residências eram providas de fossa séptica para o esgotamento sanitário e havia coleta domiciliar para o lixo. Cerca de dois terços das mães tinham entre 20 e 30 anos de idade, porém 16,4\% eram menores de 20 anos. Quanto à situação de emprego, $76,4 \%$ das genitoras trabalhavam no lar e cerca de $60 \%$ tinham menos de oito anos de escolaridade.

A mediana da idade das crianças hospitalizadas foi oito meses com intervalo interquartil entre dois e 21 meses (41\% tinham menos de seis e $62,4 \%$ até 12 meses), 33,6\% delas não foram amamentadas. A diarreia do tipo aquosa foi predominante, e as fezes foram consideradas como disentéricas em $22,9 \%$ das crianças (Tabela 1). No momento da hospitalização $32,4 \%$ das crianças foram consideradas como desnutridas, $25 \%$ apresentava febre, cerca de $70 \%$ apresentava vômitos e $60 \%$ estavam desidratadas. Das 140 crianças com diarreia $24(17,1 \%)$ eram menores de dois meses e conforme orientações do Ministério da Saúde do Brasil não tinham indicação de ser vacinadas para o rotavírus. ${ }^{18}$ Não foi possível obter o cartão vacinal/caderneta de saúde da criança de $32,8 \%$ das 116 crianças com indicação da vacina para rotavírus, $16(13,8 \%)$ não foram vacinadas e 62 $(53,4 \%)$ tinham uma ou duas doses.

Das 140 coproculturas obtidas, $96(68,5 \%)$ foram positivas para E. coli, Shigella spp. ou 
Distribuição de frequência das crianças menores de cinco anos hospitalizadas por diarreia aguda, segundo as condições socioeconômicas, demográficas e clínicas. Instituto de Medicina Integral Prof. Fernando Figueira, janeiro de 2010 a fevereiro de 2011.

\begin{tabular}{|c|c|c|c|c|c|}
\hline $\begin{array}{l}\text { Variáveis socioeconômicas } \\
\text { e demográficas }\end{array}$ & $N=140$ & $\%$ & Variáveis clínicas & $N=140$ & $\%$ \\
\hline Idade (meses) & & & Prematuridadea & & \\
\hline$<6$ & 56 & 41,0 & $\operatorname{sim}$ & 25 & 17,9 \\
\hline 6 a 12 & 30 & 21,4 & Não & 113 & 80,7 \\
\hline$>12$ & 54 & 38,6 & & & \\
\hline \multicolumn{3}{|l|}{ Sexo } & Peso ao nascer (gramas)a & & \\
\hline Masculino & 76 & 54,3 & $<2500$ & 30 & 21,4 \\
\hline Feminino & 64 & 45,7 & $\geq 2500$ & 95 & 67,9 \\
\hline \multicolumn{3}{|l|}{ Local de moradiaa } & \multicolumn{3}{|l|}{ Aleitamento materno (meses) } \\
\hline Recife e Região Metropolitana & 97 & 69,3 & Não amamentada & 47 & 33,6 \\
\hline \multirow[t]{2}{*}{ Interior de Pernambuco e outros Estados } & 40 & 28,6 & $<3$ & 39 & 27,9 \\
\hline & & & $\geq 3$ & 54 & 38,6 \\
\hline \multicolumn{6}{|l|}{ Renda per capita mensal familiar (SMR)a } \\
\hline$\leq 0,5$ & 117 & 83,6 & Vacinação para rotavírusb & & \\
\hline \multirow[t]{2}{*}{$>0,5$} & 18 & 12,9 & Nenhuma dose & 16 & 13,8 \\
\hline & & & Uma ou duas doses & 62 & 53,4 \\
\hline Tipo de habitaçãoa & & & Não apresentou cartão & 38 & 32,8 \\
\hline Permanente & 130 & 92,9 & & & \\
\hline \multirow[t]{2}{*}{ Improvisado } & 9 & 6,4 & Hospitalização anteriora & & \\
\hline & & & $\operatorname{Sim}$ & 46 & 32,9 \\
\hline Número de cômodos da moradia & & & Não & 91 & 65,0 \\
\hline 1 ou 2 & 12 & 8,6 & & & \\
\hline$>2$ & 128 & 91,4 & $\begin{array}{l}\text { Estado nutricionala } \\
\text { (escore z peso/idade)c }\end{array}$ & & \\
\hline Densidade de moradores por domicílio & & & Não desnutrido ( $\geq-2 \mathrm{z})$ & 94 & 67,6 \\
\hline 2 a 4 pessoas & 75 & 53,6 & Desnutrido $(<-2 \mathrm{z})$ & 45 & 32,4 \\
\hline \multirow[t]{2}{*}{$\geq 5$ pessoas } & 65 & 46,4 & & & \\
\hline & & & Tipo de diarreia & & \\
\hline Abastecimento de água & & & Aquosa & 108 & 77,1 \\
\hline Canalização interna & 131 & 93,6 & Disenteria & 32 & 22,9 \\
\hline \multirow[t]{2}{*}{ Outros } & 9 & 6,4 & & & \\
\hline & & & Presença de febrea, d & & \\
\hline Esgotamento sanitárioa & & & Sim & 35 & 25,0 \\
\hline Rede geral ou fossa séptica & 124 & 88.6 & Não & 103 & 73,6 \\
\hline \multirow[t]{2}{*}{ Outros } & 15 & 10,7 & & & \\
\hline & & & Presença de vômito & & \\
\hline Destino do lixoa & & & Sim & 96 & 68,6 \\
\hline Coleta domiciliar & 115 & 82,1 & Não & 44 & 31,4 \\
\hline \multirow[t]{2}{*}{ Outros } & 24 & 17,1 & & & \\
\hline & & & Estado de hidratação & & \\
\hline Idade da mãe (anos) & & & Hidratado & 59 & 42,1 \\
\hline$\leq 19$ & 23 & 16,4 & Desidratado & 81 & 57,9 \\
\hline 20 a 30 & 91 & 65,0 & & & \\
\hline \multirow[t]{3}{*}{$>30$} & 26 & 18,6 & Evolução & & \\
\hline & & & Alta & 139 & 99,3 \\
\hline & & & Óbito & 1 & 0,7 \\
\hline
\end{tabular}


Distribuição de frequência das crianças menores de cinco anos hospitalizadas por diarreia aguda, segundo as condições socioeconômicas, demográficas e clínicas. Instituto de Medicina Integral Prof. Fernando Figueira, janeiro de 2010 a fevereiro de 2011.

\begin{tabular}{|c|c|c|c|c|c|}
\hline $\begin{array}{l}\text { Variáveis socioeconômicas } \\
\text { e demográficas }\end{array}$ & $N=140$ & $\%$ & Variáveis clínicas & $N=140$ & $\%$ \\
\hline \multicolumn{6}{|l|}{ Escolaridade materna (anos) } \\
\hline$<8$ & 81 & 57,9 & - & - & \\
\hline$\geq 8$ & 59 & 42,1 & & & \\
\hline \multicolumn{6}{|l|}{ Ocupação da genitoraa } \\
\hline Trabalha no lar & 107 & 76,4 & - & - & \\
\hline Trabalha fora de casa & 32 & 22,9 & & & \\
\hline
\end{tabular}

Salmonella spp. com isolamento de 99 bactérias (Tabela 2). Isolou-se um único microorganismo em 93 culturas e dois microorganismos em três amostras. Em nove das 44 culturas restantes não houve crescimento bacteriano e em 35 delas foi observado crescimento de flora normal.

A frequência do isolamento de EPEC e de EIEC entre as 140 crianças com diarreia foi 6,4 e 2,9\% respectivamente (Tabela 2). As EPEC detectadas conforme reação de aglutinação com soro anti E. coli enteropatogênica foram assim classificadas: dois casos do grupo B (sorogrupos O114, O125, O142 e O158) e sete do grupo C (sorogrupos O86, O126, O127 e O128). Todas as amostras de EIEC agluti- naram com o antissoro polivalente A $(\mathrm{O} 28 \mathrm{ac}, \mathrm{O} 29$, O136, O144 e O152).

O isolamento de cepas de EPEC, EIEC comparado com as demais coproculturas (Tabela 3) realizadas foi semelhante na disenteria e na diarreia aquosa (razão entre prevalências $=1,01$ IC95\%= $0,21-4,39 p=0,61$ ). Os nove pacientes com EPEC tinham menos de 12 meses de idade, dois tinham fezes disentéricas e quatro usaram antimicrobianos. A partir de um dos pacientes que apresentou fezes disentéricas foi isolado EPEC e Salmonella spp. Os quatro pacientes com EIEC tinham entre um e 30 meses de idade, um tinha fezes disentéricas e três usaram antimicrobianos.

Tabela 2

Distribuição de frequência das crianças menores de cinco anos hospitalizadas por diarreia aguda segundo microrganismos isolados nas coproculturas. Instituto de Medicina Integral Prof. Fernando Figueira, janeiro de 2010 a fevereiro de 2011.

\begin{tabular}{|c|c|c|}
\hline & $\mathbf{N}$ & $\%$ \\
\hline Coproculturas & 140 & 100,0 \\
\hline Microrganismos isolados a & 99 & \\
\hline EPEC (E.coli enteropatogênica) & 9 & 6,4 \\
\hline EIEC (E.coli enteroinvasora) & 4 & 2,9 \\
\hline Outras E.coli b & 80 & 57,1 \\
\hline Salmonella spp. & 3 & 2,1 \\
\hline Shigella spp. (S.sonnei e S.flexneri) & 3 & 2,1 \\
\hline Negativas ou flora normal & 44 & 31,4 \\
\hline
\end{tabular}


Razão entre as prevalências das crianças menores de cinco anos hospitalizadas por diarreia aguda, microrganismos isolados nas coproculturas, uso de antimicrobianos e escolha de ceftriaxona como antibioticoterapia empírica segundo o tipo de diarreia. Instituto de Medicina Integral Prof. Fernando Figueira, janeiro de 2010 a fevereiro de 2011.

\begin{tabular}{|c|c|c|c|c|c|c|}
\hline & \multicolumn{2}{|c|}{ Disenteria } & \multicolumn{2}{|c|}{$\begin{array}{l}\text { Diarreia } \\
\text { aquosa }\end{array}$} & \multirow[t]{2}{*}{$\begin{array}{l}\text { Razão entre } \\
\text { prevalências }\end{array}$} & \multirow[t]{2}{*}{$p$} \\
\hline & $\mathrm{N}$ & $\%$ & $\mathrm{~N}$ & $\%$ & & \\
\hline Coproculturas & 32 & 22,9 & 108 & 77,1 & & \\
\hline Isolamento EPEC e EIEC & 3a & 9,3 & 10 & 9,2 & 1,01 & 0,61 \\
\hline Outros resultados & 29 & 90,7 & 98 & 90,8 & $(0,21-4,39)$ & \\
\hline Isolamento Salmonella e Shigella spp. & $3 b$ & 9,3 & 3 & 2,7 & 3,62 & 0,13 \\
\hline Outros resultados & 29 & 90,7 & 105 & 97,3 & $(0,55-24,10)$ & \\
\hline \multirow[t]{2}{*}{ Uso de antibiótico } & 19 & 59,4 & 42 & 38,9 & 2,3 & 0,06 \\
\hline & & & & & $(0,96-5,55)$ & \\
\hline \multicolumn{7}{|l|}{ Tipo de antibiótico } \\
\hline Ceftriaxona & 10 & 52,6 & 18 & 42,9 & 1,48 & 0,66 \\
\hline Outros antimicrobianos & 9 & 47,3 & 24 & 57,1 & $(0,44-5,06)$ & \\
\hline Ácido nalidíxico & 2 & & 2 & & & \\
\hline Cloranfenicol & 1 & & 0 & & & \\
\hline Ciprofloxacina & 1 & & 2 & & & \\
\hline $\begin{array}{l}\text { Cefalotina, amoxacilina, ampicilina } \\
\text { associada ou não à gentamicina }\end{array}$ & 5 & & 20 & & & \\
\hline
\end{tabular}

$\mathrm{EPEC}=E$. coli enteropatogênica; $\mathrm{EIEC}=E$. coli enteroinvasora; a 1 EIEC e 2 EPEC: um deles com co-infecção EPEC e Salmonella spp; b 2 Shigella spp. e 1 Salmonella spp: um deles co-infecção EPEC e Salmonella spp.

O isolamento de cepas de Shigella spp. e Salmonella spp. (Tabela 3) foi 3,62 vezes mais frequente na disenteria que na diarreia aquosa (razão entre prevalências $=3,62$ IC $95 \%=0,55-24,10$ $p=0,13$ ).

Foi iniciada antibioticoterapia empírica nas primeiras 24 horas de hospitalização para quase metade das crianças com diarreia. Entre as crianças que fizeram uso de antimicrobianos foi observado se a idade era menor ou igual a um mês, se o aspecto das fezes era aquoso ou disentérico e se era desnutrida (Tabela 4). Crianças com disenteria fizeram 2,3 vezes mais uso de antimicrobianos (razão entre prevalências $=2,3$ IC95\% $=0,96-5,55 p=0,06)$. Entre as 45 crianças consideradas desnutridas, $37,8 \%$ (17) receberam antibióticos (razão entre prevalên- cias $=0,69 \mathrm{IC} 95 \%=0,32-1,51 p=0,41)$. A ceftriaxona, isoladamente (Tabela 3 ), foi o antimicrobiano mais utilizado, sobretudo na disenteria quando comparado com a diarreia aquosa (razão entre prevalências $=1,48$ IC $95 \%=0,44-5,06 p=0,66$ ).

$\mathrm{Na}$ Tabela 5 foi apresentado o perfil de sensibilidade dos isolados bacterianos: $82,7 \%$ das E. coli (não EPEC e EIEC) foram sensíveis ao ácido nalidíxico; A sensibilidade das E.coli (não EPEC e EIEC), das EPEC e das EIEC foi inferior a $60 \%$ para ampicilina e sulfametoxazol/trimetoprima. A sensibilidade de todos isolados bacterianos de E. coli (incluindo EPEC e EIEC) foi aproximadamente igual ou superior a $90 \%$ para a ciprofloxacina, aminoglicosídeos e cefalosporinas de terceira geração testadas. 
Razão entre as prevalências do tipo de diarreia, desnutrição e faixa etária menor ou igual a um mês das crianças menores de cinco anos hospitalizadas por diarreia aguda de acordo com antibioticoterapia empírica. Instituto de Medicina Integral Prof. Fernando Figueira, janeiro de 2010 a fevereiro de 2011.

\begin{tabular}{|c|c|c|c|c|c|c|}
\hline & \multicolumn{4}{|c|}{ Antibioticoterapia empírica } & \multirow{3}{*}{$\begin{array}{l}\text { Razão entre } \\
\text { prevalências }\end{array}$} & \multirow{3}{*}{$p$} \\
\hline & \multicolumn{2}{|c|}{ Sim } & \multicolumn{2}{|c|}{ Não } & & \\
\hline & $\mathrm{N}$ & $\%$ & $\mathrm{~N}$ & $\%$ & & \\
\hline Uso de antibióticos & 61 & 43,6 & 79 & 56,4 & & \\
\hline \multicolumn{7}{|l|}{ Tipo de diarreia } \\
\hline Disenteria & 19 & 59,4 & 13 & 40,6 & 2,30 & 0,06 \\
\hline Aquosa & 42 & 38,9 & 66 & 61,7 & $(0,96-5,55)$ & \\
\hline \multicolumn{7}{|l|}{ Desnutrição } \\
\hline Sim & 17 & 37,8 & 28 & 62,2 & 0,69 & 0,41 \\
\hline Não & 44 & 46,8 & 50 & 53,2 & $(0,32-1,51)$ & \\
\hline \multicolumn{7}{|l|}{ Idade (meses) } \\
\hline$\leq 1$ & 13 & 54,2 & 11 & 45,8 & 1,67 & 0,35 \\
\hline$>1$ & 48 & 41,4 & 68 & 58,6 & $(0,64-4,43)$ & \\
\hline
\end{tabular}

\section{Tabela 5}

Sensibilidade das bactérias isoladas nas fezes das crianças hospitalizadas por diarreia aguda segundo os antimicrobianos testados. Instituto de Medicina Integral Prof. Fernando Figueira, janeiro de 2010 a fevereiro de 2011.

\begin{tabular}{|c|c|c|c|c|c|c|c|c|c|c|}
\hline \multirow{2}{*}{$\begin{array}{l}\text { Antimicrobiano } \\
\text { testado }\end{array}$} & \multicolumn{2}{|c|}{ E. coli a(75) } & \multicolumn{2}{|c|}{ EPEC (9) } & \multicolumn{2}{|c|}{ EIEC (4) } & \multicolumn{2}{|c|}{ Shigella spp (3) } & \multicolumn{2}{|c|}{ Salmonella spp (3) } \\
\hline & $\mathrm{N}$ & $\%$ & $\mathrm{~N}$ & $\%$ & $\mathrm{~N}$ & $\%$ & $\mathrm{~N}$ & $\%$ & $\mathrm{~N}$ & $\%$ \\
\hline Ácido nalidíxico & 62 & 82,7 & 8 & 88,9 & 3 & 75,0 & 3 & 100,0 & 3 & 100,0 \\
\hline Ampicilina & 19 & 25,3 & 1 & 11,1 & 1 & 25,0 & 0 & - & 1 & 33,0 \\
\hline Ceftazidima & 71 & 94,7 & 9 & 100,0 & 4 & 100,0 & 3 & 100,0 & 3 & 100,0 \\
\hline Ceftriaxona & 71 & 94,7 & 9 & 100,0 & 4 & 100,0 & 2 & 66,7 & 3 & 100,0 \\
\hline Ciprofloxacina & 70 & 93,3 & 8 & 88,9 & 4 & 100,0 & 3 & 100,0 & 3 & 100,0 \\
\hline Cloranfenicol & 64 & 85,3 & 9 & 100,0 & 4 & 100,0 & 3 & 100,0 & 3 & 100,0 \\
\hline Sulfa/Trimetoprima & 31 & 41,3 & 5 & 55,6 & 1 & 25,0 & 0 & - & 3 & 100,0 \\
\hline Gentamicina & 70 & 93,3 & 9 & 100,0 & 4 & 100,0 & 3 & 100,0 & 3 & 100,0 \\
\hline Amicacina & 75 & 100,0 & 9 & 100,0 & 4 & 100,0 & 3 & 100,0 & 3 & 100,0 \\
\hline
\end{tabular}

$\mathrm{EPEC}=E$. coli enteropatogênica; $\mathrm{EIEC}=E$. coli enteroinvasora; a $E$. coli isoladas não tipadas como EPEC ou EIEC;

()$=$ número de cepas submetidas ao teste de sensibilidade; $\mathrm{N}=$ número de cepas sensíveis; $\%=$ percentual de sensibilidade. 


\section{Discussão}

Dentre as etiologias bacterianas a E.coli enteropatogênica (EPEC) está historicamente associada à diarreia infantil nos países em desenvolvimento. ${ }^{7}$ Vários estudos realizados entre os anos 1980 e 1990 reportaram alta incidência de EPEC com taxas que variaram entre 27 e $42 \%$ sendo considerada como a causa principal da diarreia bacteriana nos menores de dois anos, principalmente nas crianças entre 6 e 12 meses. 7,8 A taxa de $6,4 \%$ observada no nosso estudo corresponde à referida em estudos realizados a partir do ano 2000 que demonstram forte declínio da prevalência de diarreia por EPEC $^{19}$ com frequências entre 5 e $11 \%$. Vale assinalar que as EPEC isoladas no nosso estudo foram em menores de 12 meses de idade o que mostra conformidade com os trabalhos publicados. 19

O declínio na prevalência de EPEC nos países em desenvolvimento coincide com a diminuição de casos de diarreia justificados pela melhora das condições de higiene e de saneamento básico da população.9,19,20 O programa de saneamento urbano realizado em 1997 na cidade de Salvador no Brasil, por exemplo, mostrou efetividade na prevenção da diarreia em crianças menores de três anos, reduzindo em $22 \%$ a prevalência desta doença após melhoria de $80 \%$ na cobertura de esgotamento sanitário nos lares. ${ }^{21}$ Embora os pacientes do nosso estudo tenham renda per capita familiar menor ou igual a U\$4,60 por dia, a melhora das condições de aprovisionamento de água encanada nas residências, esgotamento sanitário e coleta de lixo domiciliar adequados quando comparada com o estudo realizado nos anos 1990 no IMIP,22 podem justificar, como nas publicações citadas, a prevalência de EPEC aqui apresentada.

A frequência encontrada para $\operatorname{EIEC~}(2,9 \%)$ foi semelhante às exibidas em trabalhos conduzidos no Brasil11,23 e em países desenvolvidos nos anos 1990 e 2000.7 Os relatos de estudos epidemiológicos mostram a presença de EIEC geralmente em surtos, onde a transmissão através de alimentos e água contaminados é geralmente identificada. ${ }^{7}$

A limitação técnica na investigação bacteriana de rotina nos laboratórios clínicos pode deixar diversos quadros de diarreia infantil sem o esclarecimento do agente etiológico. ${ }^{7}$ As técnicas moleculares usadas atualmente na identificação dos fatores de virulência dos diversos tipos de E. coli como os ensaios de Reação em Cadeia da Polimerase (PCR) que detectam os genes que codificam esses fatores, funcionam como diagnóstico definitivo e confiável.7 Devido a limitações metodológicas do nosso estudo, entre as demais $E$. coli $(57,1 \%)$ isoladas e que não foram tipadas pelo antissoros convencionais poderiam estar incluídas outros grupos de E.coli não patogênica, outras EPEC ou EIEC, ou outras categorias de DEC se fossem usados os métodos moleculares para identificação. Cepas identificadas previamente por métodos sorológicos como pertencentes aos sorogrupos clássicos de EPEC, ao serem analisadas através da técnica PCR possuíam algum gene de virulência de EPEC típica, EPEC atípica, EAEC, ETEC e EHEC. 20,23

O isolamento de três $(2,1 \%)$ Salmonella spp nas 140 crianças do nosso estudo está em concordância com trabalho realizado após a década de $1990 \mathrm{em}$ São Paulo. ${ }^{9}$ No entanto, a frequência de $2,1 \%$ para Shigella spp apresentada aqui foi um pouco abaixo de estudos brasileiros desta mesma época, 8,9 embora bem próxima dos achados de $4,1 \%$ em estudo realizado em João Pessoa nos anos 2000.24 Embora mais frequente, não foi demonstrada associação da presença de Shigella spp e Salmonella spp na disenteria ou na diarreia aquosa quando comparada com o isolamento de outras bactérias $(p=0,13)$.

Em relação à sensibilidade aos antimicrobianos, neste estudo observaram-se altos níveis de resistência tanto das EPEC, EIEC quanto das outras E. coli à ampicilina e sulfametoxazol/trimetoprima $\mathrm{e}$ cerca de $90 \%$ ou mais de sensibilidade de todas as cepas de E.coli, incluindo as EPEC e EIEC, aos aminoglicosídeos, ciprofloxacina e cefalosporinas de terceira geração testadas, refletindo a tendência demonstrada por vários autores no Brasil e México.25-28

Recomendações de uso de antimicrobianos nas diarreias são consideradas especiais: recémnascidos, pacientes com suspeita de disseminação sistêmica do processo infeccioso, imunodeprimidos, casos graves de disenteria e cólera. ${ }^{29}$ Neste estudo foi instituída antibioticoterapia para cerca de metade das crianças hospitalizadas. No entanto, um estudo de série de casos realizado em 2005 com 36 crianças menores de cinco anos internadas com diarreia no IMIP apresentou índice ainda maior $(91,6 \%)$ de prescrição de antibióticos. ${ }^{30}$ Embora quatro entre dez crianças com diarreia aquosa tenham feito uso de antimicrobianos, a decisão do médico assistente de iniciar antibiótico foi 2,3 vezes mais frequente entre os pacientes com disenteria quando comparados com aqueles que tinham diarreia aquosa, próximo de significância estatística $(p=0,06)$. A ceftriaxona foi o antimicrobiano mais utilizado e estes dados reacendem uma discussão sobre o uso inadequado de antibióticos assim como da possibilidade de indução de multirresistência na 
terapia empírica.

Mesmo apresentando baixo rendimento familiar per capita, a maioria dos pacientes do estudo possuía adequado fornecimento de água, esgotamento sanitário e coleta de lixo, apropriados. Estas condições sociodemográficas favoráveis sugerem menor frequência encontrada neste estudo para EPEC, semelhante aos dados de estudos atuais. Os dados da sensibilidade aos antimicrobianos encon-

\section{Referências}

1. UNICEF (The United Nations Children's Fund). Diarrhoea: why children are still dying and what can be done. Geneve; 2009

2. Silva GAP. Diarreia aguda: fatores de risco e manejo. Rev Pediatr (Ceará). 2002; 3: 5-9

3. Silva GAP, Lira PIC, Lima MC. Fatores de risco para doença diarréica no lactente: um estudo caso-controle. Cad Saúde Pública. 2004; 20: 589-95.

4. Gurgel RQ, Ilozue C, Correia JB, Centenari C, Oliveira $\mathrm{SM}$, Cuevas LE. Impact of rotavirus vaccination on diarrhoea mortality and hospital admissions in Brazil. Trop Med Int Health. 2011; 16: 1180-4

5. Correia JB, Patel MM, Nakagomi O, Montenegro FM, Germano EM, Correia NB, Cuevas LE, Parashar UD, Cunliffe NA, Nakagomi T. Effectiveness of monovalent rotavirus vaccine (Rotarix) against severe diarrhea caused by serotypically unrelated G2P [4] strains in Brazil. J Infect Dis. 2010; 201: 363-9.

6. Tate JE, Burton AH, Boschi-Pinto C, Steele AD, Duque J, Parashar UD, the WHO-coordinated Global Rotavirus Surveillance Network. 2008 estimate of worldwide rotavirus-associated mortality in children younger than 5 years before the introduction of universal rotavirus vaccination programmes: a systematic review and meta-analysis. Lancet Infect Dis. 2011; 3099(11): 70253-5.

7. Nataro JP, Kaper JB. Diarrheagenic Escherichia coli. Clin Microbiol Rev. 1998; 11: 142-201.

8. Fagundes Neto U, Schmitz LG, Scaletsky I. Acute diarrhea due to enterpathogenic Escherichia coli: epidemiological and clinical features in Brasília, Brasil. Int J Infect Dis. 1996; 1: 65-9.

9. Souza EC, Martinez MB, Taddei CR, Mukai L, Gillio AE, Racz ML, Silva L, Ejzenberg B, Okay Yassuhiko. Perfil etiológico das diarreias agudas em crianças atendidas em São Paulo. J Pediatr. 2002; 78: 31-8.

10. Kaper JB, Nataro JP, Mobley HL. Pathogenic Escherichia coli. Nat Rev Microbiol. 2004; 2: 123-40.

11. Almeida MTG, Silva RM, Donaire LM, Moreira LE, Martinez MB. Enteropatógenos associados com diarreia aguda em crianças. J Pediatr. 1998; 74: 291-8.

12. Qadri F, Svennerholm A-M, Faruque ASG, Sack RB Enterotoxigenic Escherichia coli in developing countries epidemiology, microbiology, clinical features, treatment, and prevention. Clin Microbiol Rev. 2005; 18: 465-83.

13. WHO (World Health Organization). Public health review of the enterohaemorrhagic Escherichia coli outbreak in trados neste estudo reforçam a importância do conhecimento do agente etiológico que pode estar envolvido na diarreia aguda. Constantes atualizações dos profissionais de saúde em relação ao manejo clínico da diarreia, assim como o conhecimento das taxas de resistências bacterianas locais fazem parte das estratégias recomendadas pela Organização Mundial da Saúde visando o uso racional dos antimicrobianos.
Germany. Geneve; 2011.

14. Harrington SM, Dudley EG, Nataro JP. Pathogenesis of enteroaggregative Escherichia coli infection. FEMS Microbiol Lett. 2006: 254: 12-8.

15. Brasil. Ministério da Saúde. Indicadores e dados básicos (IDB) 2009. [Acesso em 7 Nov 2011]. Disponível em: http//tabnet.datasus.gov.br/cgi/idb2009/matriz.ht.

16. Clinical and Laboratory Standards Institute. Performance standard for antimicrobial susceptibility testing; twentieth informational supplement. CLSI document M100-S20-U. Wayne, $\mathrm{Pa} ; 2010$.

17. Kuczmarski RJ, Ogden CL, Guo SS. Growth charts for the United States: Methods and development. National Center for Health Statistics.Vital Health Stat 11(246). CDC; 2002.

18. Brasil. Ministério da Saúde. Secretaria de Vigilância em Saúde. Departamento de Vigilância Epidemiológica. Doença diarreica por rotavírus: vigilância epidemiológica e prevenção pela vacina oral de rotavírus humano - VORH. Brasília, DF; 2008.

19. Franzolin MR, Alves RCB, Keller R, Gomes TAT, Beutin L, Barreto ML, Milroy C, Strina A, Ribeiro H, Trabulsi LR. Prevalence of diarrheagenic Escherichia coli in children with diarrhea in Salvador, Bahia, Brasil. Mem Inst Oswaldo Cruz. 2005; 100: 359-63.

20. Trabulsi LR, Keller R, Gomes TAT. Typical and atypical enteropathogenic Escherichia coli. Emerg Infec Dis. 2002; 8: 508-13.

21. Barreto ML, Genser B, Strina A, Teixeira MG, Assis AMO, Rego RF, Teles CA, Prado MS, Matos SMA, Santos DN, Santos LA, Cairncross S. Effect of city-wide sanitation programme on reduction in rate of childhood diarrhoea in northeast Brazil: assessment by two cohort studies. Lancet. 2007; 370: 1622-8

22. Vanderlei LCM, Silva GAP, Braga JU. Fatores de risco para internamento por diarreia aguda em menores de dois anos: estudo de caso-controle. Cad Saúde Pública. 2003; 19: 45563

23. Campos LC, Franzolin MR, Trabulsi LR. Diarrheagenic Escherichia coli categories among the traditional EPEC O serogroups. Mem.Inst. Oswaldo Cruz. 2004. 99: 545-52.

24. Moreno ACR, Fernandes-filho A, Gomes TAT, Ramos STS, Montemor LPG, Tavares VC, Santos-Filho L, Irino K, Martinez MB. Etiology of childhood diarrhea in the northeast of Brazil: significant emergent diarrheal pathogens. Diagn Microbiol Infect Dis. 2010; 66: 50-7. 
25. Santos RD, Santana JS, Barretto JR, Andrade MGM, Silva LR. Epidemiological and microbiological aspects of acute bacterial diarrhea in children from Salvador, Bahia, Brazil. Braz J Infect Dis. 2005; 9: 77-83.

26. Garcia PG, Silva VL, Diniz CG. Occurrence and antimicrobial drug susceptibility patterns of commensal and diarrheagenic Escherichia coli in fecal microbiota from children with and without acute diarrhea. J Microbiol. 2011; 49: 46-52.

27. Estrada-García T, Cerna JF, Paheco-Gil L, Velázquez RF, Ochoa TJ, Torres J, DuPont HL. Drug-resistant diarrheogenic Escherichia coli, Mexico. Emerg Infect Dis.
$2005 ; 11: 1306-8$

28. OMS (Organização Mundial da Saúde). Cuidados hospitalares para crianças. Normas para o manejo de doenças frequentes com recursos limitados. OMS; 2005.

29. Brasil. Ministério da Saúde do Brasil. Doenças infecciosas e parasitárias. Brasília, DF; 2008 (Série B. Textos Básicos de Saúde).

30. Pontual JPS, Falbo AR, Gouveia JS. Estudo etiológico da diarreia em crianças hospitalizadas no Instituto Materno Infantil Prof. Fernando Figueira, IMIP, em Recife, Pernambuco. Rev Bras Saúde Matern Infant. 2006; 6: 511-

Recebido em 3 de janeiro de 2012

Versão final apresentada em 23 de março de 2012

Aprovado em 16 de abril de 2012 